\title{
USO DE DROGAS LÍCITAS E ILÍCITAS NA GRAVIDEZ: A IMPORTÂNCIA DOS ESCLARECIMENTOS DOS RISCOS AS GESTANTES
}

\author{
USO DE DROGAS LICITAS E ILICITAS EN EL EMBARAZO: LA IMPORTANCIA \\ DE ACLARAR LOS RIESGOS PARA LAS MUJERES EMBARAZADAS
}

\section{USE OF LICIT AND ILLICIT DRUGS IN PREGNANCY: THE IMPORTANCE OF RISK CLAIMS AS PREGNANT}

\author{
Larissa Tainá ${ }^{1}$; Deyse Aíla ${ }^{2}$; Alessandra Alves ${ }^{3}$; Laniedja Jacó ${ }^{4}$; Robervam Pedroza ${ }^{5}$
}

DOI: https://doi.org/10.31692/978-65-991061-9-4.111-114

\section{INTRODUÇÃO}

O período gestacional é caracterizado como fase de diversas transformações físicas e psicológicas na mulher. Segundo Leitão (1998) a gravidez requer um esforço suplementar de síntese e de reorganização da estabilidade, do qual pode resultar um acréscimo de vulnerabilidade, capaz de constituir um fator de risco para a saúde mental da mulher. Alguns fatores adversos como gravidez não planejada, situação econômica frágil, família desestruturada podem levar essas mulheres a procurarem as drogas como forma de fugir da realidade. As drogas são caracterizadas como qualquer substância que ao ser introduzida no organismo causa uma alteração no mesmo.

O projeto buscou conhecer melhor as drogas lícitas e ilícitas e suas implicações do uso durante a gravidez, a partir do estudo das propriedades dessas substâncias, o perfil socioeconômico demográfico dessas mulheres, bem como o acompanhamento dos processos do parto, nascimento e no crescimento e desenvolvimento da criança. Sendo assim, a pesquisa trouxe possibilidades de lidar com essas mulheres nas situações que visam à promoção da saúde e prevenção de agravos, através de ações educativas, com a perspectiva de sensibilização quanto aos riscos que o álcool e as outras drogas podem causar ao binômio mãe-filho.

É de extrema importância que esse público obtenha informações e acompanhamento adequado para redução de danos e o uso seja desestimulado e minimizado, evitando assim complicações, tanto na gravidez quanto no parto e puerpério. A cidade onde foi desenvolvida a pesquisa ainda não possui na sua rede serviços de saúde voltados para a promoção, prevenção e reabilitação para o uso de substâncias psicoativas (álcool e outras drogas ilícitas), nem tampouco a modalidade de Centro de Atenção Psicossocial voltado para álcool e outras drogas

\footnotetext{
${ }^{1}$ Bacharelado em Enfermagem, IFPE, LALAPERFA29@gmail.com

2 Bacharelado em Enfermagem, IFPE, deyramalho99@gmail.com

${ }^{3}$ Bacharelado em Enfermagem, IFPE, alessandraalveslins14@gmail.com

${ }^{4}$ Bacharelado em Enfermagem, IFPE, lanypocao@gmail.com

${ }^{5}$ Mestre em Saúde da Família, IFPE, robervam@pesqueira.ifpe.edu.br
} 
(CAPS-AD). Por conseguinte, essa população fica em situação de vulnerabilidade, dada a escassez de serviços na rede, bem como as limitações das equipes de saúde da família em suprir a atenção necessária a todas as mulheres envolvidas. O público-alvo foram as gestantes que fazem uso de drogas lícitas e ilícitas, com finalidade de identificar e analisar as condições de saúde materno- filial associado aos riscos do uso das drogas durante a gravidez. O estudo foi desenvolvido na cidade de Pesqueira, Pernambuco, na Unidade Básica de Saúde (UBS), localizada no bairro São Francisco.

\section{RELATO DE EXPERIÊNCIA}

A pesquisa foi classificada como descritiva e exploratória desenvolvida na Unidade Básica de Saúde São Francisco no período de fevereiro a dezembro de 2018, localizada na cidade de Pesqueira em Pernambuco.

O projeto foi apresentado na Secretaria de Saúde de Pesqueira, na qual foram identificadas as potenciais gestantes da UBS. A partir de então, foi feita a apresentação para as enfermeiras e toda a equipe da UBS. Com o intuito de uma melhor organização da pesquisa foi estabelecido como critério de inclusão no estudo: ser gestante cadastrada na Unidade Básica de Saúde (UBS) São Francisco e que fizesse uso de drogas lícitas ou ilícitas no período gestacional ou puerperal. Assim como critério de exclusão ser gestante que não estivessem cadastradas na Unidade Básica de Saúde (UBS) São Francisco.

A partir do primeiro contato com as gestantes, público-alvo do projeto de extensão, percebeu-se as dificuldades de acesso. Diante dessa situação fez-se necessário estabelecer vínculos, com as gestantes, primeiro apresentando o projeto e depois através de ações educativas de saúde, como oficinas de musicoterapias, rodas de conversas apresentando quais os riscos e agravos que as drogas podem causar, tirando dúvidas apresentadas por elas, troca de saberes, oficina sobre manobras de primeiros socorros em bebês, abordando sobre alimentação saudável, além de outros temas relacionados à gravidez. Para fins de consolidação das atividades e para otimizar o registro, as atividades eram resumidas em um diário de campo, com base nas rodas de conversa e nas demais atividades desenvolvidas entre os extensionistas, profissionais e as gestantes.

Através de rodas de conversa com as gestantes cadastradas na UBS São Francisco foram identificadas as necessidades de esclarecimentos sobre os riscos e consequências para binômio mãe-filho que o uso de drogas lícitas e ilícitas ocasionaria.

Com o apoio da equipe foram realizadas ações educativas com ênfase na prevenção do uso de drogas lícitas e ilícitas, além de enfatizar a importância do acompanhamento regular no 
pré-natal.

\section{CONSIDERAÇÕES}

O uso de drogas lícitas e ilícitas no período gestacional ainda é um grave problema de saúde pública, precisa ser averiguado desde o pré-natal para que os profissionais de saúde possam informar as mães, pais e familiares sobre os riscos e consequências para binômio. Assim faz-se necessário o embasamento de estratégias especificas de repasse de informações, qualificação de profissionais, ações conjuntas de equipes multiprofissionais com o mesmo intuito, bem como, a correlação com a literatura que faz alusão à temática e dessa forma possam ser amenizados os efeitos nocivos, de modo a garantir uma boa qualidade de vida para o bebê, a mãe e sua família.

Quanto ao município onde foi o cenário do trabalho, é importante que a gestão municipal aborde mais o tema e o difunda nas demais unidades, haja vista que a problemática uma dimensão sistêmica e não pontual. Dessa forma, uma estratégia importante seria uma política de educação e promoção à saúde mais abrangente para que a temática fosse articulada em todas as unidades.

Há de se considerar que o município não possui nenhum serviço especializado de saúde que atenda essa demanda, ficando a cargo das unidades de saúde da família o acompanhamento dessas usuárias do serviço com todas as fragilidades que a rede já possui, sobretudo para os indivíduos que fazem uso inadequado de álcool e outras substâncias psicoativas.

A instituição de ensino, no exercício do seu papel de educar e formar, tem se inserido no contexto dos serviços, aproximando da realidade dos serviços para fortalecer o SUS municipal. Dessa forma pode colaborar com a gestão municipal na elaboração de políticas que melhore a qualidade de vida dos cidadãos, e em especial, as gestantes que fazem uso dessas substâncias, através das atividades de ensino, de pesquisa e de extensão.

\section{REFERÊNCIAS}

ANGELUCCI, Mateus A. Exposição ao álcool na gestação e sintomas psiquiátricos na idade escolar. 2010. 85p. Dissertação (Mestrado) - Universidade de São Paulo - Faculdade de Ciências Farmacêuticas, Ribeirão Preto, 2010. Disponível em: file://C:/Users/2351691/Downloads/dissertacao_original\%20(2).pdf. Acesso em: 08/12/2018.

BRASIL. Ministério da Saúde. Secretaria de Atenção à Saúde. Pré-Natal e Puerpério: atenção qualificada e humanizada: manual técnico. Brasília, 2006. Disponível em: http://bvsms.saude.gov.br/bvs/publicacoes/manual_pre_natal_puerperio_3ed.pdf. Acesso em: $10 / 12 / 2018$. 
BRASIL. Ministério da Saúde. Secretaria de Vigilância em Saúde. Plano emergencial de combate ao uso nocivo de álcool e outras drogas. Brasília, DF; 2010. Disponível em: http://bvsms.saude.gov.br/bvs/sus/pdf/junho/MS_plano_emergencial_combate_uso_alcool_dr ogas_0406.pdf. Acesso em 11/10/2018.

CERVO, Amado L. Metodologia Científica. São Paulo: Pearson Prentice Hall, 2007.

LEITÃO, M. L. H. A Gravidez de Alto Risco Genético: contributo para a compreensão dos fenómenos psicológicos envolvidos. 1998. Tese de Mestrado em Psicologia Clínica do Desenvolvimento não publicada, Faculdade de Psicologia e de Ciências da Educação da Universidade de Coimbra.

McDERMOTT, R.; CAMPBEL, S.; LI, M.; McCULLOCH, B. The health and 4. nutrition of young indigenous women in north Queensland - intergenerational implications of poor food quality, obesity, diabetes, tobacco smoking and alcohol use. Public Health Nutr. v.11, n.6, p.1-7, 2009.

SEGRE, C. A.M. Efeitos do álcool na gestante, no feto e no recém-nascido. São Paulo: Sociedade de Pediatria de São Paulo, 2010.

YAMAGUCHI, Eduardo T.; CARDOSO, Monica M. S. C.; TORRES, Marcelo L. A.; ANDRADE, Arthur G. Drogas de Abuso e Gravidez. Revista de Psiquiatria Clínica, São Paulo, v. 35, 2008. Disponível em: http://www.scielo.br/scielo.php?script=sci_arttext\&pid= S0101-60832008000700010. Acesso em: 08/12/2018. 